Open Access

\title{
Preliminary experience on the safety and tolerability of mechanical "insufflation- exsufflation" in subjects with artificial airway
}

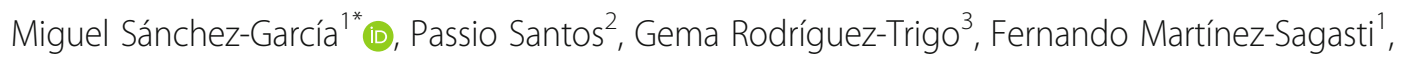
Tomás Fariña-González', Ángela del Pino-Ramírez , Carlos Cardenal-Sánchez¹, Beatriz Busto-González', Mónica Requesens-Solera ${ }^{1}$, Mercedes Nieto-Cabrera ${ }^{1}$, Francisco Romero-Romero ${ }^{1}$ and Antonio Núñez-Reiz ${ }^{1}$

\footnotetext{
* Correspondence: miguelsanchez. hcsc@gmail.com

Presented in abstract form at the 30th Annual Congress of the European Society of Intensive Care Medicine, September 23-27, 2017, Vienna, Austria. The manuscript is not under consideration for publication elsewhere.

${ }^{1}$ Critical Care Department, Hospital Clínico San Carlos, c/Prof. Martín Lagos s/n, 28040 Madrid, Spain Full list of author information is available at the end of the article
}

\begin{abstract}
Background: Catheter suctioning of respiratory secretions in intubated subjects is limited to the proximal airway and associated with traumatic lesions to the mucosa and poor tolerance. "Mechanical insufflation-exsufflation" exerts positive pressure, followed by an abrupt drop to negative pressure. Potential advantages of this technique are aspiration of distal airway secretions, avoiding trauma, and improving tolerance.
\end{abstract}

Methods: We applied insufflation of $50 \mathrm{cmH}_{2} \mathrm{O}$ for $3 \mathrm{~s}$ and exsufflation of -45 $\mathrm{cmH}_{2} \mathrm{O}$ for $4 \mathrm{~s}$ in patients with an endotracheal tube or tracheostomy cannula requiring secretion suctioning. Cycles of 10 to 12 insufflations-exsufflations were performed and repeated if secretions were aspirated and visible in the proximal artificial airway. Clinical and laboratory parameters were collected before and 5 and 60 min after the procedure. Subjects were followed during their ICU stay until discharge or death.

Results: Mechanical insufflation-exsufflation was applied 26 times to 7 male and 6 female subjects requiring suctioning. Mean age was $62.6 \pm 20$ years and mean Apache II score $23.3 \pm 7.4$ points. At each session, a median of $2(I Q R ~ 1 ; 2)$ cycles on median day of intubation 11.5 (IQR 6.25; 25.75) were performed. Mean insufflation tidal volume was $1043.6 \pm 649.9 \mathrm{ml}$. No statistically significant differences were identified between baseline and post-procedure time points. Barotrauma, desaturation, atelectasis, hemoptysis, or other airway complication and hemodynamic complications were not detected. All, except one, of the mechanical insufflation-exsufflation sessions were productive, showing secretions in the proximal artificial airway, and were well tolerated.

Conclusions: Our preliminary data suggest that mechanical insufflation-exsufflation may be safe and effective in patients with artificial airway. Safety and efficacy need to be confirmed in larger studies with different patient populations.

Trial registration: EudraCT 2017-005201-13 (EU Clinical Trials Register).

Keywords: Mechanical insufflation-exsufflation, Airway clearance, Safety, Artificial airway, Endotracheal intubation, Respiratory tract secretions, Secretion suctioning, Endotracheal aspiration 


\section{Background}

Aspiration of respiratory secretions is a frequently needed procedure in intubated subjects, which is performed whenever respiratory secretions accumulate. The conventional method consists of inserting a sterile catheter through the endotracheal tube or tracheostomy cannula connected to a negative pressure port into the trachea until resistance is met [1]. Its effect is therefore limited to the trachea and carina and efficacy is reduced in the presence of dense secretions. Frequent complications include traumatic lesions to the mucosa, poor tolerance [2], and pain [3], as well as, mostly transient, respiratory and hemodynamic adverse events [4, 5]. Airway clearance devices providing mechanically assisted cough or mechanical insufflation-exsufflation (MIE), in contrast to manually assisted cough, are being used to facilitate aspiration of tracheobronchial secretions. They simulate the physiological cough mechanism by applying positive pressure to the airway followed by an abrupt decrease to a negative pressure [6]. Experience with non-invasive secretion clearance with MIE has accumulated in non-critically ill patients with neuromuscular diseases (NMD), both chronic ventilatordependent [7-9] and spontaneously breathing subjects [8, 10], hospitalized or at home [11]. The specific indication for the use of a mechanical airway clearance device is the lack of effective cough in spite of respiratory physiotherapy, with the aim to reduce the risk for atelectasis and respiratory tract infection. The usual interface is a face mask, although the intended use of the devices also includes patients with endotracheal intubation $[6,12]$.

Compared to conventional secretions suctioning with a sterile catheter inserted through the endotracheal tube or tracheostomy cannula, potential advantages of MIE are a more effective aspiration of distal airway secretions, avoidance of direct trauma to the airway mucosa, and improved tolerance of the aspiration maneuver. On the other hand, however, the short "recruitment" maneuver during the positive pressure phase may increase the risk of respiratory and hemodynamic complications [6, 13-15]. The few published experiences reporting on its use in intensive care do not report complications associated with the use of MIE [10, 16-18], although concerns about the safety of the technique in critically ill patients have been voiced $[19,20]$. The technique has been introduced in clinical practice in our department to support respiratory tract secretion suctioning in subjects needing frequent suctioning, to facilitate weaning and/or to reduce the risk of reintubation. We report on our initial experience in evaluating the safety of MIE in an unselected intubated patient population of a broad range of severity.

\section{Methods}

We report on our experience in a short series of patients in whom MIE was first used. Cases with endotracheal or tracheostomy tubes requiring aspiration of tracheobronchial secretions were selected, irrespective of degree of respiratory failure, hemodynamic instability or other organ dysfunctions, primary or secondary acute lung dysfunction, atelectasis, tracheobronchitis, pneumonia, and intracranial hypertension. The only inclusion criterion for aspiration of respiratory secretions with the "Cough Assist" ${ }^{\mathrm{Tm}}$ " airway clearance device was therefore the need for secretion suctioning, regardless of severity or degree of respiratory or other organ dysfunctions.

Subjects on any assisted mode of ventilation requiring aspiration of secretions by clinical judgment or ventilator display curves [21] were connected to a mechanical 
aspiration device (Cough Assist E70 ${ }^{\mathrm{m}}$, Respironics, Philips) without previously performing conventional secretion suctioning. Insufflation plateau was set at $50 \mathrm{cmH}_{2} \mathrm{O}$, with a duration of $3 \mathrm{~s}$, followed by an exsufflation phase at a negative pressure of $-45 \mathrm{cmH}_{2} \mathrm{O}$ maintained for $4 \mathrm{~s}$. These insufflation-exsufflation pressures are slightly above the \pm $40 \mathrm{cmH}_{2} \mathrm{O}$ recommended by the manufacturer, which are meant to be applied by face mask mainly, and were chosen to overcome resistance to air flow exerted by the artificial airways [22]. The device also applies oscillation at $16 \mathrm{~Hz}$ during both insufflation and exsufflation plateaus. The synchronized, i.e., patient-triggered "cough track" mode with "high" inhale flow was programmed for all 26 sessions. Study subjects were not instructed to exhale or try to cough during the exsufflation phase.

Cycles of 10 to 12 MIE were applied and only repeated if productive. A cycle was defined as productive if secretions were visible in the proximal segment of the artificial airway at the 10th to 12th insufflation-exsufflation. Secretions aspirated to the lumen of the proximal segment of the endotracheal tube or tracheostomy cannula were aspirated with a sterile catheter with the tip remaining in the proximal artificial airway. A tubing with bacterial heat-moisture exchange filters (Intersurgical "Inter-Therm HMEF" with luer port) at both ends was used to attach the device to the artificial airway, with an oxygen flow of $8 \mathrm{l} / \mathrm{min}$ connected to the luer port of the filter close to the MIE device (Fig. 1).

Clinical and biochemical variables were collected at baseline, immediately before MIE, and 5 and $60 \mathrm{~min}$ after the sessions. We recorded ventilator modes and parameters, arterial or venous blood gases, and hemodynamic parameters. Half of the cases had an arterial catheter inserted.

Subjects were disconnected from the ventilator tubing to be connected to the tubing of the airway clearance device. Immediately after MIE, mechanically ventilated and spontaneously breathing subjects were returned to their baseline ventilator status, without any change in settings, mode, or inspiratory fraction of oxygen $\left(\mathrm{FiO}_{2}\right)$.

Subjects were followed for complications potentially related to MIE during their ICU stay until discharge or death, including review of daily chest X-rays.

The approved use of CoughAssist ${ }^{\mathrm{m}}$ includes secretion suctioning in subjects with artificial airway $[6,12]$ and is available and commonly applied in our critical care department.

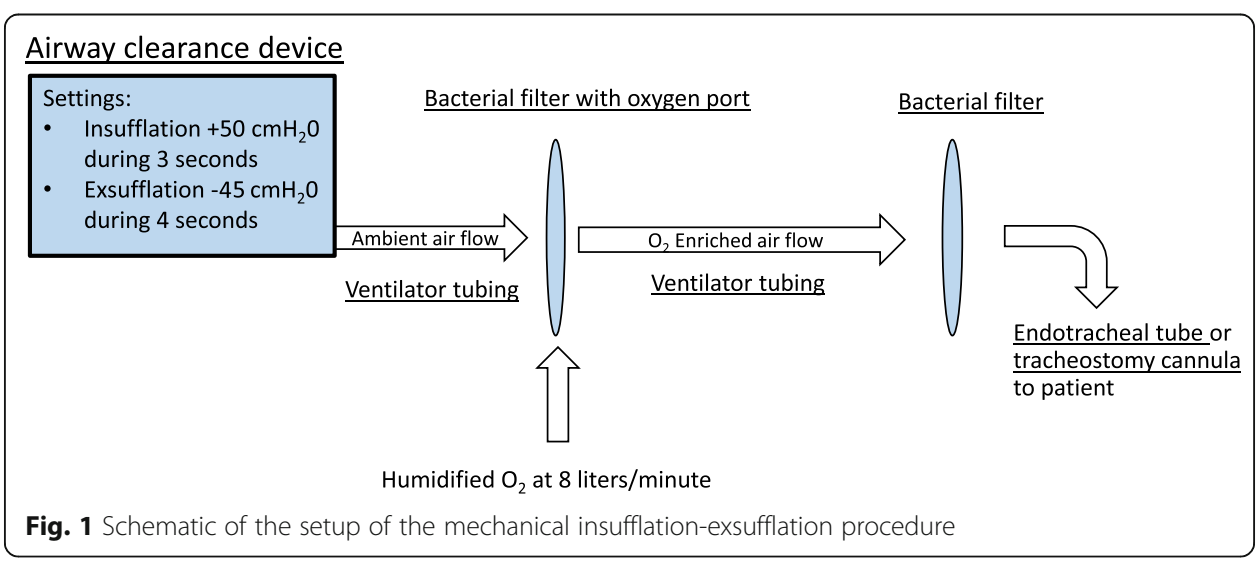




\section{Statistical analyses}

Data were entered in a Microsoft Excel spreadsheet. Quantitative variables collected at baseline and $60 \mathrm{~min}$ after the procedure or at baseline and the 5- and 60-min time points were compared by Student's $t$ test, analysis of variance for repeated measurements, or non-parametric tests, as appropriate. Qualitative variables were compared using the chi-square or Fisher tests. Baseline ventilator status was only compared to 60 min post-intervention parameters, i.e., without the 5 -min post-intervention data, because, per protocol, subjects were returned to baseline parameters immediately after MIE. We did not perform a sample size calculation but rather chose to study a small number of subjects exposed to our routine MIE parameters under close clinical and laboratory monitoring conditions to maximize safety.

\section{Results}

We studied 13 subjects, 7 males and 6 females, with a mean age of $62.6 \pm 20$ years and a mean Apache II score at ICU admission of $23.3 \pm 7.4$ points, who were connected to the airway clearance device a total of 26 times on median day 11.5 (IQR 6.25; 28.25) after ICU admission and 11.5 (IQR 6.25; 25.75) after endotracheal intubation. Per session, a median of 2 (IQR $1 ; 2)$ cycles were performed. The device was connected 16 times to a tracheostomy tube and 10 times to an endotracheal tube. The characteristics of subjects are listed in Table 1.

One patient with a baseline intracranial pressure of $17 \mathrm{cmH}_{2} \mathrm{O}$ showed an increase to $28 \mathrm{cmH}_{2} \mathrm{O}$ during the $3 \mathrm{~s}$ of the first mechanical insufflation, with pressures remaining around 0 in the second and all subsequent MIE cycles and an intracranial pressure of $15 \mathrm{cmH} 2 \mathrm{O}$ at $60 \mathrm{~min}$ after the procedure. Another patient, under extracorporeal membrane oxygenation for a bronchopleural fistula developing after major heart surgery, also suffering from hospital-acquired pneumonia, was being ventilated with plateau airway pressures below $20 \mathrm{cmH}_{2} \mathrm{O}$. MIE pressures were therefore reduced to +20 and $40 \mathrm{cmH}_{2} \mathrm{O}$, respectively, in this patient. No pleural air leak was observed during the procedure, while abundant purulent secretions were aspirated.

Table 2 shows hemodynamic and respiratory parameters collected at baseline and 5 and 60 min after MIE, without statistically significant differences between time points for any variable, except for a significant increase of pulse oximetry oxygen saturation and $\mathrm{PaO}_{2}$.

MIE was considered successful, i.e., respiratory tract secretions were aspirated and visible in the proximal segments of the artificial airway, in all except one patient, in whom no secretions were evidenced. The procedure was well tolerated in all cases, and no additional sedatives or analgesic medications or changes in vasopressor infusion rates were required. No barotrauma, i.e., pneumothorax, nor atelectasis were observed on daily follow-up chest X-rays. No patient developed desaturation, suggesting derecruitment, or hemoptysis or other airway complications.

\section{Discussion}

The data presented here are a first step in the evaluation of the safety and efficacy of mechanical insufflation-exsufflation (MIE) in subjects with artificial airway. We did not detect adverse events occurring during or after the procedure potentially related to MIE with the parameters employed in this cohort of subjects. Recent versions of airway 


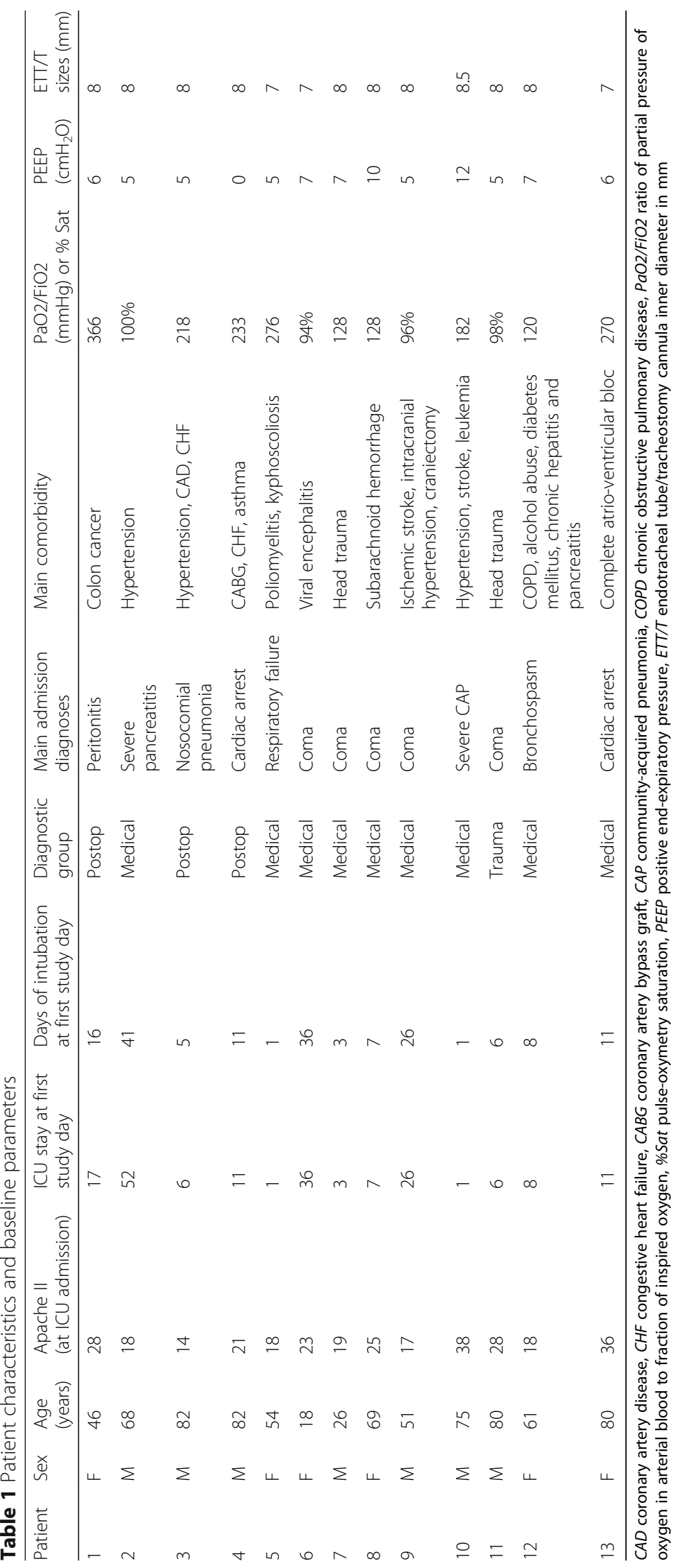


Table 2 Baseline and follow-up respiratory and hemodynamic parameters

\begin{tabular}{|c|c|c|c|c|}
\hline & Baseline & $5^{\prime}$ & $60 "$ & $p$ \\
\hline Temperature, ${ }^{\circ} \mathrm{C}$ & $37.3 \pm 0.82$ & & $37.4 \pm 0.7$ & ns \\
\hline Heart rate, bpm & $97.7 \pm 14.4$ & $97.1 \pm 15.1$ & $97.3 \pm 14.2$ & 0.82 \\
\hline Mean blood pressure, $\mathrm{mmHg}$ & $87 \pm 11.9$ & $87.6 \pm 14.7$ & $83.6 \pm 14.7$ & 0.57 \\
\hline Sat $\mathrm{O}_{2}, \%$ & $97.38 \pm 2.37$ & $98.3 \pm 2.2$ & $97 \pm 3.4$ & 0.04 \\
\hline $\mathrm{pHa}$ & $7.43 \pm 0.1$ & $7.38 \pm 0.1$ & $7.45 \pm 0.05$ & 0.17 \\
\hline $\mathrm{pHv}$ & $7.39 \pm 0.1$ & $7.44 \pm 0.02$ & $7.42 \pm 0.05$ & 0.13 \\
\hline $\mathrm{PaO}_{2}, \mathrm{mmHg}$ & $105.5 \pm 23.9$ & $124 \pm 55.5$ & ${ }^{*} 143 \pm 42.3$ & 0.031 \\
\hline $\mathrm{PvO}_{2}, \mathrm{mmHg}$ & $54.9 \pm 37.4$ & $34.5 \pm 4.9$ & $52.4 \pm 29$ & 0.67 \\
\hline $\mathrm{PaCO}_{2}, \mathrm{mmHg}$ & $37.5 \pm 12.6$ & $40.5 \pm 13.3$ & $35.2 \pm 8.2$ & 0.058 \\
\hline $\mathrm{PvCO}_{2}, \mathrm{mmHg}$ & $45.2 \pm 6.7$ & $44.5 \pm 3.5$ & $40.2 \pm 5.2$ & 0.15 \\
\hline Ventilator mode & & & & 0.61 \\
\hline CPAP PC-IMV & 20 & & 18 & \\
\hline MMV VC-IMV & 2 & & 1 & \\
\hline Spontaneous respiration & 4 & & 7 & \\
\hline $\mathrm{FiO}_{2}$ & $0.46 \pm 0.13$ & $0.45 \pm 0.13$ & $0.44 \pm 0.1$ & 0.73 \\
\hline $\mathrm{PaO}_{2} / \mathrm{FiO}_{2}$ & $239.8 \pm 96.8$ & $285.5 \pm 140$ & $328.7 \pm 104.7$ & 0.14 \\
\hline $\mathrm{PvO}_{2} / \mathrm{FiO}_{2}$ & $134.9 \pm 114.2$ & $105.9 \pm 3.7$ & $132.6 \pm 93.9$ & 0.96 \\
\hline Total breath, rate/min & $22.1 \pm 6.3$ & $23.5 \pm 7.1$ & $20.7 \pm 5.9$ & 0.10 \\
\hline Minute volume, $1 /$ min & $10.6 \pm 3.6$ & $11.0 \pm 3.2$ & $9.6 \pm 2.6$ & 0.13 \\
\hline Tidal volume, ml & $524.1 \pm 106.6$ & $496.3 \pm 118.4$ & $493.2 \pm 139$ & 0.15 \\
\hline PEEP, mmHg & $5.3 \pm 2.9$ & $5.3 \pm 2.9$ & $4.6 \pm 3.2$ & 0.45 \\
\hline Peak inspiratory pressure, $\mathrm{cmH}_{2} \mathrm{O}$ & $23.6 \pm 7.8$ & $24.0 \pm 8.1$ & $22.3 \pm 5.6$ & 0.17 \\
\hline Plateau pressure, $\mathrm{cmH}_{2} \mathrm{O}$ & $21.9 \pm 5.1$ & $22.5 \pm 5.4$ & $20.9 \pm 4.4$ & 0.14 \\
\hline \multicolumn{5}{|l|}{ Lung compliance } \\
\hline Dynamic & $17.7 \pm 9.5$ & $16.3 \pm 9.4$ & $17.6 \pm 9.6$ & 0.4 \\
\hline Static, $\mathrm{ml} / \mathrm{cmH}_{2} \mathrm{O}$ & $18.7 \pm 8.8$ & $17.2 \pm 9.1$ & $19.1 \pm 9.3$ & 0.33 \\
\hline CA tidal volume, $\mathrm{ml}$ & $1043.6 \pm 649.9$ & & & \\
\hline
\end{tabular}

$\mathrm{Bpm}$ beats per minute, $\mathrm{Sat} \mathrm{O}_{2}$ pulse-oximetry oxygen saturation, $\mathrm{pHa}$ arterial $\mathrm{pH}, \mathrm{pHv}$ venous $\mathrm{pH}, \mathrm{PaO}_{2}$ arterial oxygen partial pressure, $\mathrm{PvO}_{2}$ venous oxygen partial pressure, $\mathrm{PaCO}_{2}$ arterial $\mathrm{CO} 2$ partial pressure, $\mathrm{PvCO}_{2}$ venous $\mathrm{CO}_{2}$ partial pressure, $C P A P$ assisted pressure ventilation, $M M V$ minimal mandatory ventilation, BiPAP controlled pressure mandatory ventilation, IPPV volume-targeted pressure control ventilation, PEEP positive end-expiratory pressure, CA Cough Assist *Significant difference from baseline

clearance devices allow for application of insufflation and exsufflation, i.e., positive and negative pressures, of up to 70 and $-70 \mathrm{cmH}_{2} \mathrm{O}$, respectively, with duration of inspiratory and expiratory plateau pressures of up to $5 \mathrm{~s}$ and optional concomitant high frequency oscillation during both. For this initial approach to the technique, we chose to apply our routine, more conservative, +50 and $-45 \mathrm{cmH}_{2} \mathrm{O}$ and 3 and $4 \mathrm{~s}$ duration settings. We also usually provide continuous oxygen flow during the procedure because the airway clearance device uses ambient air without supplemental oxygen.

The significant increase of partial arterial oxygen pressure observed after MIE may be due to the administration of a continuous flow of oxygen at $8 \mathrm{l} / \mathrm{min}$ at the filter port adjacent to the artificial airway and to the clearance of airway secretions with a concomitant recruitment effect of $3 \mathrm{~s}$ of positive pressure at $50 \mathrm{cmH}_{2} \mathrm{O}$. If the latter is true, it could have contributed to avoid de-recruitment due to disconnection from positive pressure mechanical ventilation, as is the case for the conventional secretion suctioning procedure. 
The effect of the short 3-s $+50-\mathrm{cmH}_{2} \mathrm{O}$ "recruitment maneuver" is supported by the observed increase of arterial oxygenation from 5 to $60 \mathrm{~min}$ after MIE. Thus, in our short series of critically ill intubated patients, disconnection did not result in loss of positive pressure, alveolar collapse, and desaturation [19, 20]. Conversely, conventional suctioning implies disconnection and drop of airway pressure, as well as interruption of ventilation and oxygenation. In the only randomized trial comparing MIE with the conventional suctioning procedure in critically ill intubated patients [16], most of the complications actually occurred in the control group, except for one patient in the study group developing hypotension. Blood pressure may have remained stable in our cohort because of our patients having an adequate intravascular volume status, although we did not monitor any direct parameter to measure it. Additionally, as the reduction in venous return due to positive thoracic pressure during the first insufflation is immediately compensated by the negative thoracic exsufflation pressure, which increases venous return, fluctuations in blood pressure may not be clinically detected or relevant.

Gastric distension is a complication reported only in non-intubated patients with NMD, where MIE is applied by face mask. In a previous study, 2 out of 11 subjects developed stomach distension, with one being complicated by gastroesophageal reflux requiring endotracheal intubation [10].

The importance of our preliminary data on secretion suctioning relates to the scarcity of studies concerning MIE in acute care settings that have been published. The role of MIE is well established in neuromuscular disease patients in chronic and acute settings but not as a routine in critical care. The few published experiences reporting on the use of MIE in intensive care include a single randomized study showing a significant reduction of reintubation when employing MIE immediately before and during $48 \mathrm{~h}$ after extubation [16]. The combination of post-extubation non-invasive mechanical ventilation with pre- and post-extubation MIE was associated with successful extubation in a population of 157 "unweanable" patients, $89 \%$ of whom suffered from NMD [18]. Another publication describes a single case of traumatic quadriplegia successfully weaned from mechanical ventilation supported in part by MIE applied immediately after extubation [17]. A small study with a historical control group showed a reduction in the number of subjects needing endotracheal intubation for invasive mechanical ventilation in a group of patients with NMD admitted to intensive care for acute respiratory insufficiency with or without respiratory tract infections, in whom MIE was applied with a face mask [10]. An analogy between patients suffering from NMD and the critical ill who develop polyneuropathy and myopathy [23], both unable to cough their respiratory tract secretion, can be established to justify further investigation of MIE in critically ill intubated patients.

An additional reason for further assessing the safety and efficacy of MIE is the clinical relevance and frequency of the main adverse events associated with conventional suctioning techniques, as well as its limited effectiveness. The tip of the catheter exerts negative pressure only within a small area of the proximal airway, due, at least in part, to lack of proximal sealing. In addition, repeated insertion of the suctioning catheter causes traumatic injury to the mucosa. Tolerance of endotracheal aspiration is poor and reported to constitute one of the most painful maneuvers in critically ill patients [3], and administration of analgesia, with or without sedatives, prior to the maneuver has been advocated [2]. Finally, a frequently observed complication is desaturation 
associated with disconnection from the ventilator, particularly in patients with severe respiratory insufficiency and high PEEP settings. Although our preliminary findings suggest that MIE may achieve airway clearance at a reduced morbidity cost, several limitations need to be acknowledged. The main caveats of our study results are the small sample size and the relative clinical stability of most patients, thus preventing us from drawing conclusions for patients in higher severity groups, like those with ARDS or severe hemodynamic dysfunction. Also, not being a controlled study, the observed safety and efficacy data need to be further evaluated in future randomized controlled trials.

\section{Conclusions}

The potential benefits of MIE, beyond airway clearance during weaning and avoiding reintubation [16], remain to be proven and potentially include reduction of adverse events and improved tolerance, as well as prevention and/or treatment of respiratory tract infection in intubated patients. The current report only provides data of clinical practice and, therefore, as a first step, safety of the technique needs to be confirmed over a broader range of severity and in studies of comparative randomized design.

\section{Abbreviations}

Apache II: Acute Physiology and Chronic Health Evaluation; FiO2: Inspiratory fraction of oxygen; ICU: Intensive care unit; IQR: Interquartile range; MIE: Mechanical insufflation-exsufflation; NMD: Neuromuscular diseases

\section{Acknowledgements}

We would like to thank our nursing staff for their help and contribution to the procedures involved in this study. The study was performed at the Critical Care Department, Hospital Clínico San Carlos, Madrid, Spain.

\section{Funding}

Respironics, Philips provided the Cough Assist E70 ${ }^{\mathrm{TM}}$ airway clearance device and had no role in the design of the study and collection, analysis, and interpretation of data nor in writing the manuscript.

The airway clearance device (CoughAssist ${ }^{\mathrm{TM}}$, Respironics Philips) was provided by Respironics, Philips, Spain. The study received no additional funding.

Availability of data and materials

Please contact the author for data requests.

Authors' contributions

All authors contributed to the design of the protocol, selection of patients, performing the intervention, and reviewing the manuscript.

Ethics approval and consent to participate

The study was evaluated and approved by the institutional Ethics Review Board (Comité de Ética e Investigación Clínica. Ref 17/395-E_P) for publication, with a waiver for informed consent.

\section{Consent for publication}

The Ethics Review Board approved the study protocol and the publication of the collected anonymized patient data.

Competing interests

The authors declare that they have no competing interests.

\section{Quick look}

Current knowledge

Current practice of respiratory secretion suctioning in subjects with endotracheal tubes or tracheostomy cannulas consists of insertion of a sterile catheter. This maneuver is frequently associated with pain and agitation and traumatic injury to the tracheobronchial mucosa and occasionally causes more severe, lifethreatening complications. It is also relatively inefficient, because it only aspirates proximal airway secretions. What this paper contributes to our knowledge

This paper provides the first set of data about the safety of an alternative technique, called mechanical insufflationexsufflation (MIE), with the potential of being well tolerated and more effective. The device applies positive pressure followed by an abrupt fall to negative pressure, thereby imitating cough and generating outward flow. We did not detect any adverse event in the present small study, in which we attempted airway secretion clearance with MIE. MIE was well tolerated and produced respiratory secretions in all except one of the suctioning attempts. 


\section{Publisher's Note}

Springer Nature remains neutral with regard to jurisdictional claims in published maps and institutional affiliations.

\section{Author details}

${ }^{1}$ Critical Care Department, Hospital Clínico San Carlos, c/Prof. Martín Lagos s/n, 28040 Madrid, Spain. ${ }^{2}$ Physiotherapy and Rehabilitation Service, Hospital Clínico San Carlos, c/Prof. Martín Lagos s/n, 28040 Madrid, Spain. ${ }^{3}$ Service of Pulmonology, Hospital Clínico San Carlos, c/Prof. Martín Lagos s/n, 28040 Madrid, Spain.

Received: 3 January 2018 Accepted: 12 March 2018

Published online: 03 April 2018

\section{References}

1. Care AAoR (2010) AARC clinical practice guidelines. Endotracheal suctioning of mechanically ventilated patients with artificial airways 2010. Respir Care 55:758-764

2. Robleda G, Roche-Campo F, Membrilla-Martínez L, Fernández-Lucio A, Villamor-Vázquez M, Merten A, Gich I, Mancebo J, Català-Puigbó E, Baños JE (2016) Evaluación del dolor durante la movilización y la aspiración endotraqueal en pacientes críticos. Med Int 40:96-104

3. Puntillo KA, Max A, Timsit JF, Vignoud L, Chanques G, Robleda G, Roche-Campo F, Mancebo J, Divatia JV, Soares M, Ionescu DC, Grintescu IM, Vasiliu IL, Maggiore SM, Rusinova K, Owczuk R, Egerod I,

Papathanassoglou ED, Kyranou M, Joynt GM, Burghi G, Freebairn RC, Ho KM, Kaarlola A, Gerritsen RT, Kesecioglu J, Sulaj MM, Norrenberg M, Benoit DD, Seha MS, Hennein A, Periera FJ, Benbenishty JS, Abroug F, Aquilina A, Monte JR, An Y, Azoulay E (2014) Determinants of procedural pain intensity in the intensive care unit. The Europain(R) study. Am J Respir Crit Care Med 189:39-47

4. Liu XW, Jin Y, Ma T, Qu B, Liu Z (2015) Differential effects of endotracheal suctioning on gas exchanges in patients with acute respiratory failure under pressure-controlled and volume-controlled ventilation. Biomed Res Int 2015:941081

5. Jongerden IP, Rovers MM, Grypdonck MH, Bonten MJ (2007) Open and closed endotracheal suction systems in mechanically ventilated intensive care patients: a meta-analysis. Crit Care Med 35:260-270

6. Fernandez-Carmona A, Olivencia-Pena L, Yuste-Ossorio ME, Penas-Maldonado L, Grupo de Trabajo de Unidad de Ventilacion Mecanica Domiciliaria de G, (2017) Ineffective cough and mechanical mucociliary clearance techniques. Med Int. https://doi.org/10.1016/j.medin.2017.1005.1003.

7. Sancho J, Servera E, Vergara P, Marin J (2003) Mechanical insufflation-exsufflation vs. tracheal suctioning via tracheostomy tubes for patients with amyotrophic lateral sclerosis: a pilot study. Am J Phys Med Rehabil 82:750-753

8. Pillastrini P, Bordini S, Bazzocchi G, Belloni G, Menarini M (2006) Study of the effectiveness of bronchial clearance in subjects with upper spinal cord injuries: examination of a rehabilitation programme involving mechanical insufflation and exsufflation. Spinal Cord 44:614-616

9. Bach JR, Goncalves M (2004) Ventilator weaning by lung expansion and decannulation. Am J Phys Med Rehabil 83:560-568

10. Vianello A, Corrado A, Arcaro G, Gallan F, Ori C, Minuzzo M, Bevilacqua M (2005) Mechanical insufflationexsufflation improves outcomes for neuromuscular disease patients with respiratory tract infections. Am J Phys Med Rehabil 84:83-88 discussion 89-91

11. Bento J, Goncalves M, Silva N, Pinto T, Marinho A, Winck JC (2010) Indications and compliance of home mechanical insufflation-exsufflation in patients with neuromuscular diseases. Arch Bronconeumol 46:420-425

12. Healthcare P (2013) Philips Respironics Cough Assist T70 suggested protocol. In: Editor (ed)^(eds) Book Philips Respironics Cough Assist T70 suggested protocol. Philips Respironics, Philips Electronics, Amsterdam

13. Fan E, Checkley W, Stewart TE, Muscedere J, Lesur O, Granton JT, Freitag AP, Jacka M, Ferguson ND, Meade MO (2012) Complications from recruitment maneuvers in patients with acute lung injury: secondary analysis from the lung open ventilation study. Respir Care 57:1842-1849

14. Suri P, Burns SP, Bach JR (2008) Pneumothorax associated with mechanical insufflation-exsufflation and related factors. Am J Phys Med Rehabil 87:951-955

15. Westermann EJA, Jans M, Gaytant MA, Bach JR, Kampelmacher MJ (2013) Pneumothorax as a complication of lung volume recruitment. J Bras Pneumol 39:382-386

16. Goncalves MR, Honrado T, Winck JC, Paiva JA (2012) Effects of mechanical insufflation-exsufflation in preventing respiratory failure after extubation: a randomized controlled trial. Crit Care 16:R48

17. Chang JE, Park SH, Do SH, Song IA (2013) Successful weaning from mechanical ventilation in the quadriplegia patient with C2 spinal cord injury undergoing C2-4 spine laminoplasty—a case report. Korean J Anesthesiol 64:545-549

18. Bach JR, Goncalves MR, Hamdani I, Winck JC (2010) Extubation of patients with neuromuscular weakness: a new management paradigm. Chest 137:1033-1039

19. Esquinas Rodriguez AM, Pravinkumar E (2012) Mechanical insufflation-exsufflation in prevention of post-extubation acute respiratory failure: most welcome but must be used cautiously in critically ill patients. Crit Care 16:431

20. Kallet RH, Diaz JV (2009) The physiologic effects of noninvasive ventilation. Respir Care 54:102-115

21. Correger E, Murias G, Chacon E, Estruga A, Sales B, Lopez-Aguilar J, Montanya J, Lucangelo U, Garcia-Esquirol O, Villagra A, Villar J, Kacmarek RM, Burgueño MJ, Blanch L (2012) Interpretación de las curvas del respirador en pacientes con insuficiencia respiratoria aguda. Med Int 36:294-306

22. Guerin C, Bourdin G, Leray V, Delannoy B, Bayle F, Germain M, Richard JC (2011) Performance of the coughassist insufflation-exsufflation device in the presence of an endotracheal tube or tracheostomy tube: a bench study. Respir Care 56:1108-1114

23. Zhou C, Wu L, Ni F, Ji W, Wu J, Zhang H (2014) Critical illness polyneuropathy and myopathy: a systematic review. Neural Regen Res 9:101-110 